\title{
Antecedents of Soft-Skills in Higher Education Institutions of Saudi Arabia Study under COVID-19 Pandemic
}

\author{
Arif Malik' ${ }^{1}$, Waqar Ahmad ${ }^{2}$ \\ ${ }^{1}$ Department of Business (MIS), Jeddah International College, Jeddah, Saudi Arabia \\ ${ }^{2}$ Department of Industrial Engineering, King Abdul Aziz University, Jeddah, Saudi Arabia \\ Email: aarif.malik@jicollege.edu.sa,wahmed@kau.edu.sa
}

How to cite this paper: Malik, A., \& Ahmad, W. (2020). Antecedents of Soft-Skills in Higher Education Institutions of Saudi Arabia Study under COVID-19 Pandemic. Creative Education, 11, 1152-1161. https://doi.org/10.4236/ce.2020.117086

Received: June 9, 2020

Accepted: July 27, 2020

Published: July 30, 2020

Copyright $\odot 2020$ by author(s) and Scientific Research Publishing Inc. This work is licensed under the Creative Commons Attribution International License (CC BY 4.0).

http://creativecommons.org/licenses/by/4.0/

\begin{abstract}
Higher Education Institutions (HEIs) play an important role in development of productive academic environment for university graduates. Similarly, soft skills are an essential requirement for fresh graduates to provide and prepare them for the convenient and suitable job market. In last few months, emerging situation of COVID-19 has affected the Saudi higher education sector at large scale from business perspective by diverting the regular studies to online classes. Online classes have made it more difficult for academic staff to cope up with this deteriorating situation. This study is planned to identify numerous soft-skills, which could be important to conduct academic activities under COVID-19 crisis. Study will make an analysis focusing on the importance of soft-skills in higher education institutions before and after the COVID-19 crisis. Study collected data from both public and private sector higher educational institutions located in Jeddah, Saudi Arabia. Study observed the key role and overall impact of soft-skills to enhance the learning aptitudes under uncertain COVID-19 situation. Study will also focus on the importance of soft-skills in job success in the Saudi job market for university graduates. Study will also focus on the importance of soft-skills integration in higher education curriculum. Study will help the decision makers to plan and prepare accordingly for developing academic environment to get better job opportunities in the competitive Saudi business organizations.
\end{abstract}

\section{Keywords}

Convergent and Discriminant Validity, Composite Reliability, Average Variance Extracted 


\section{Introduction}

Higher Education Institutions (HEIs) play a key role in the development of modern education standards. HEIs are responsible in developing and maintaining a high level of academic curriculum equipped with most modern learning tools and skill. In this regards, HEIs must identify and develop set of important soft-skills and attributes to integrate into the academic curriculum of different study fields in higher education sector. These soft-skills can help the university graduates for a better candidate in the Saudi job market (Redha Al Abduwani, 2012). The main objective of the study is to identify the measures that how Saudi higher education institutions can improve the learning process under COVID-19 pandemic. Furthermore, how university graduates can be benefited in this uncertain situation by learning the proposed important soft-skills (Sharma, 2019). Business organizations have been already reporting that they need to conduct special training sessions for fresh graduates to learn and adapt the business requirements (Tang, 2020). Keeping this in view, study will contribute to enhance the importance of soft-skills to address the competitive job market concerns. Study will focus on the integration of proposed soft-skills in the higher education curriculum for different field of studies. Study will maintain a level of coordination in incorporating the course objectives, learning outcomes in accordance with the job market requirements to further strengthen the curriculum. Following is the detail of the research objectives and Saudi market problem:

\subsection{Problem Statement}

COVID-19 pandemic has shifted the regular studies paradigm to online studies using different online tools like (Zoom, 2020; https://zoom.us/), (Webex, 2020; https://www.webex.com/), (Moodle, 2020; https://moodle.com/), (WizIQ, 2020; https://www.wiziq.com/) and (Blackboard, 2020; https://www.blackboard.com). It has also affected the Saudi higher education sector at large scale from business perspective to academic activities progression. This study is planned to identify important soft skills, which could help the academic environment to perform better in the uncertain COVID-19 pandemic crisis. University graduates have an issue of being not prepared for the job market and most of them need trainings as they join the competitive job market. This is mostly happening in the engineering and technical study areas, where more focus is on technical skills instead of focusing on working environment skills. Study will address and focus on the importance of soft-skills to be integrated in the university curriculum in different study fields at higher education institutions.

\subsection{Research Objective}

Study will particularly focus on higher education institutions of Saudi Arabia under this uncertain situation of COVID-19 pandemic. Study will observe and identify the important soft-skills before and after the pandemic situation. Study will focus particularly on the fresh university graduates to cope up with the job market requirements by learning and adapting the proposed soft-skills. Further- 
more, study will assess and evaluate the importance of the soft-skills in HEIs curriculum with emphasis on before and after COVID-19 situation. Finally, study will propose recommendations for integrating the proposed soft-skills in higher education curriculum.

\section{Importance of Soft-Skills}

University education is an ongoing process for developing and preparing the university graduates for the competitive job market. Saudi higher education ministry is providing international standard opportunities and services to university students in their respective study fields. Soft-skills are playing a vital role in personality development of university graduates and known to form the personality traits, attitudes, career attributes, social intelligence and emotional intelligence quotients. This will enable them to communicate better, perform efficiently and cooperate well with others in a professional business environment (Melluso et al., 2020). Since the COVID-19 pandemic has disturbed the normal way of education, new ways and means of education has been introduced during this short period of time. Saudi higher education in compliance with the universities and colleges is ready to equip the graduates with modern education standards (Tang, 2020). The graduates must understand and learn the soft-skills knowledge effectively to get them ready to be placed in the job market. In modern times, academic education and soft-skills keep changing as per the work environment and market demands. At the same time, business organizations are complaining about the university graduates in terms of lack in soft-skills learning. They feel that they have to arrange training sessions for fresh graduates to prepare them for the job market. This argument is mostly focused on engineering and technical field of studies, as they feel that soft-skills are not part of their regular studies. This looks correct as engineers are technical professionals and they don't get involved with management and business operations but modern business demands are changing as business needs are growing (Yaacoub, Husseini, \& Choueiki, 2011). One of the most common criticism is regarding the communication skills like local, bilingual or trilingual languages of the graduate in Saudi job market (Sharma, 2019). On the other side general academic programs such as Arts, Design and Business Administration put more emphasis on learning and adopting the soft-skills during the studies (Chondekar, 2019). However, during the COVID-19 pandemic situation, it has become more important for the university graduates to learn and adopt the soft-skills. It has become difficult for both faculty members and students to handle the current academic situation as its online not on regular basis. Both will require a more solid and applied evidence of implementing academic standards in higher education institutions (Pomeroy, 2014). Hence, it is very important for higher education ministry, universities and colleges to integrate soft-skills in academic in COVID-19 pandemic situation.

\section{Literature Review}

Relevant literature is an important source of collecting the information for the 
research studies. The main objective is to determine the hypothesis for the current study. Soft-skills play an important role in developing the university graduates as per the job market requirements. These skills will help and prepare the graduates to look for the better and appropriate job in the saturated job market. There are many soft-skills discussed and addressed in the previous studies but this study will focus on soft-skills in the uncertain situation of COVID-19. Researcher has reviewed the relevant literature and found some important soft-skills, which could add value to the university graduates in addition to the knowledge of the study field. It could also help the academicians to prepare and plan the best ways and means for the university graduates. These soft skills include, Creativity $(C R T)$, it is known to generate original and unique ideas and provide solutions to resolve the issue (Sharma, 2019), Patience (PAT), is recognized to deal with different cultural environments, with different backgrounds, learning styles and intellectual abilities (Yaacoub, Husseini, \& Choueiki, 2011), Persuasion (PER), is defined as convincing others to support your innovative ideas and solutions to take into practical actions (Tang, 2020), Organization (ORG), is known to make different class activities and assessments for ensuring a smooth grading process (Chondekar, 2019), Adaptability (ADP), is recognized to perform work in changed and uncertain environment, specially in the uncertain COVID-19 situation (Bak, Jordan, \& Midgley, 2019), Leadership (LED), is the ability to inspire others and lead teams to success for achieving the ultimate objectives (Redha Al Abduwani, 2012), Teamwork (TMW), is recognized to work in a team to achieve common goals (Marinakou \& Giousmpasoglou, 2015), Time Management (TMG), is known as working under pressure as well as within strict deadlines (Sharma, 2019), Technological Skills (TCS), are means of learning and applying modern technological skills under COVID-19 situation (Bak, Jordan, \& Midgley, 2019), Conflict Resolution $(C F R)$, is known to manage differences among peers (Marinakou \& Giousmpasoglou, 2015). These soft-skills have been addressed in different research studies as per the study requirements but this particular study will focus on the uncertain situation of COVID-19. This was already a difficult task and has become more tedious when there is a technological barrier between the academic staff and the students.

\section{Research Methodology}

For data collection, quantitative method has been adopted and non-probability based convenience data sampling technique is used for the current study as recommended by the research experts (Saunders, Lewis, \& Thornhill, 2008). A questionnaire based survey in public and private sector higher education institutions was conducted by the researcher himself. Public sector universities were including King Abdulaziz University and University of Jeddah, whereas private sector college and universities were including Effat University, Dar Al-Hekma University, University of Business and Technology, Arab Open University and Jeddah International College. Questionnaire was prepared and distributed through Google Docs to General Managers, Deans and Vice Deans, Academic staff, Stu- 
dents, Head of Departments and general staff working the higher education institutions. Collected data has been verified and only valid data has been used for study and results have been analyzed by using Microsoft Excel and mainly Smart PLS3.0.

\section{Analysis and Interpretation}

For the purpose of analysis and data interpretation, researcher has performed descriptive analytical methods in accordance with study objectives and problem identified earlier. Different statistical measures like frequencies and averages were performed for the analysis purposes. Detail is given below:

\subsection{Demographic Detail}

Following graph (Figure 1) shows the overall demographic detail of the respondents, where each position is listed with female and male respondents. An online questionnaire was prepared using Google Docs to address the study objectives. For the purpose of analysis, descriptive analytical methods were deployed to perform the statistical measures like frequencies and averages. Questionnaire asked about the basic demographic information of the participant like gender and position, i.e. Managers, Deans, HODs, Teachers, Students, Staff and Others Gender and Position in the university or college. There were ten questions in four sections asking for the COVID-19 impact as (Low, Medium, High and Increase, No Change and Decrease). Last three questions were about the final opinion of the respondent's regarding the integration of soft-skills in higher education institution's curriculum. Detail is illustrated in Figure 1.

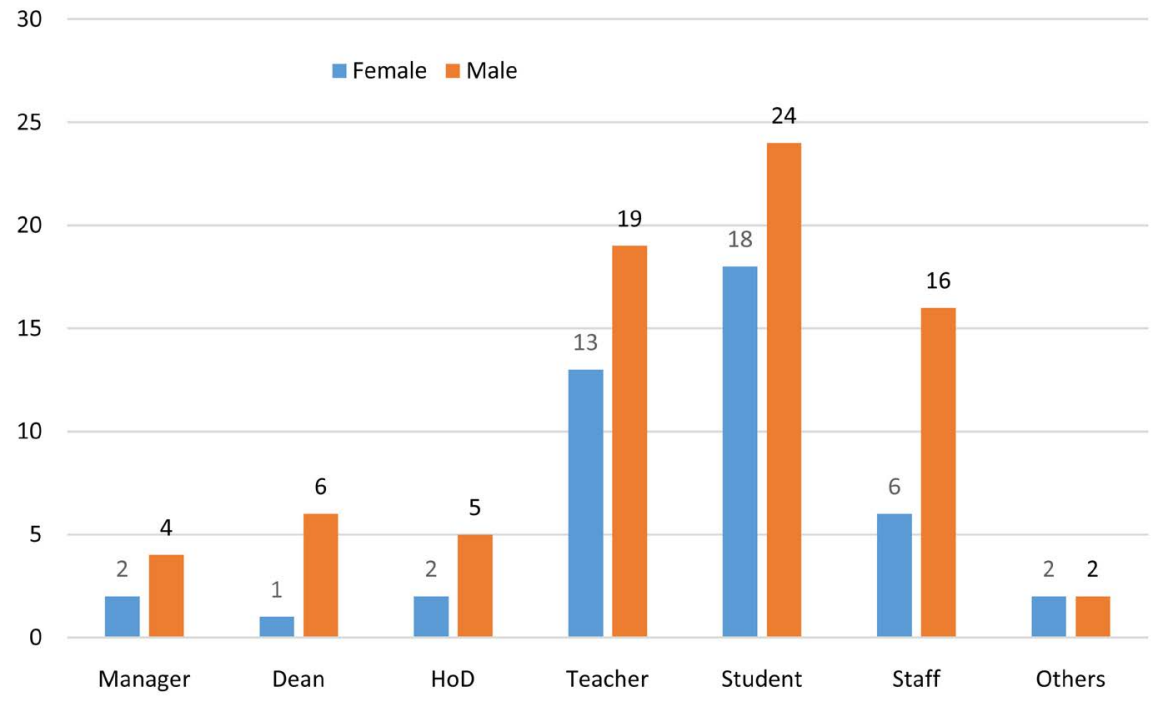

Figure 1. Soft-skills for job-market success before COVID-19.

\subsection{The Convergent Validity Analysis}

According to Hair et al., convergent validity refers to the degree to a group of variables converge in measuring a particular concept. It can be established through 
the simultaneous testing of three criteria; Factor Loadings, Composite Reliability and Average Variance Extracted. As such, the entire items loadings were examined and confirmed where AVE must be $>0.50 \mathrm{CR}$ must be $>0.70$, Cronbach's must be $>0.70$ and Loadings must be $>0.60$. However, if all other criteria of measurement model fulfil the validity and reliability requirements, we can retain some item's loading even as low as 0.40 as an acceptable level (Hair, Babin, \& Krey, 2017). The factor loadings were all significant with 0.01 level of significance, shown in Table 1. The values of Cronbach Alpha fall well above the thresh hold value while composite reliability values fall between 0.881 and 0.956 indicating that the latter values exceeded the recommended value of 0.70 (Nouf Rashed $\mathrm{Al}$ khater, 2017). Hence, results show the group of items AVE in relation to the variance shared with measurement errors. Specifically, AVE measures the variance encapsulated by indicators that relate to the assignable variance to the measurement errors. If the AVE value is 0.5 , the set of items is deemed to have sufficient convergence in measuring the construct (Hair et al., 2014). The detail is given below in Table 1.

Table 1 . Convergent validity analysis.

\begin{tabular}{|c|c|c|c|c|c|}
\hline Items & Items & Loadings & AVE & CR & Cronbach's $a$ \\
\hline \multirow{10}{*}{$\begin{array}{l}\text { Job-Success Before } \\
\text { COVID-19 (JSB) }\end{array}$} & CRT & 0.7583 & \multirow{10}{*}{0.5031} & \multirow{10}{*}{0.7532} & \multirow{10}{*}{0.7231} \\
\hline & PAT & 0.7662 & & & \\
\hline & PER & 0.7424 & & & \\
\hline & ORG & 0.7304 & & & \\
\hline & ADP & 0.7105 & & & \\
\hline & LED & 0.7201 & & & \\
\hline & TMW & 0.7022 & & & \\
\hline & TMG & 0.7201 & & & \\
\hline & TCS & 0.7010 & & & \\
\hline & CFR & 0.7301 & & & \\
\hline \multirow{10}{*}{$\begin{array}{l}\text { Job-Success After } \\
\text { COVID-19 (JSA) }\end{array}$} & CRT & 0.7223 & \multirow{10}{*}{0.5123} & \multirow{10}{*}{0.7321} & \multirow{10}{*}{0.7221} \\
\hline & PAT & 0.7341 & & & \\
\hline & PER & 0.8101 & & & \\
\hline & ORG & 0.7701 & & & \\
\hline & $\mathrm{ADP}$ & 0.6995 & & & \\
\hline & LED & 0.4053 & & & \\
\hline & TMW & 0.8196 & & & \\
\hline & TMG & 0.7858 & & & \\
\hline & TCS & 0.7735 & & & \\
\hline & CFR & 0.7229 & & & \\
\hline \multirow{5}{*}{$\begin{array}{l}\text { Soft-Skills Integration } \\
\text { Before COVID-19 (SIB) }\end{array}$} & CRT & 0.7321 & \multirow{5}{*}{0.5321} & \multirow{5}{*}{0.7322} & \multirow{5}{*}{0.7320} \\
\hline & PAT & 0.7243 & & & \\
\hline & PER & 0.7302 & & & \\
\hline & ORG & 0.7501 & & & \\
\hline & $\mathrm{ADP}$ & 0.7945 & & & \\
\hline
\end{tabular}




\begin{tabular}{|c|c|c|c|c|c|}
\hline & LED & 0.6023 & & & \\
\hline & TMW & 0.7181 & & & \\
\hline & TMG & 0.7214 & & & \\
\hline & TCS & 0.7425 & & & \\
\hline & CFR & 0.7229 & & & \\
\hline \multirow{10}{*}{$\begin{array}{l}\text { Soft-Skills Integration } \\
\text { After COVID-19 (SIA) }\end{array}$} & CRT & 0.6896 & \multirow{10}{*}{0.5532} & \multirow{10}{*}{0.7941} & \multirow{10}{*}{0.7731} \\
\hline & PAT & 0.7229 & & & \\
\hline & PER & 0.7399 & & & \\
\hline & ORG & 0.7679 & & & \\
\hline & ADP & 0.6442 & & & \\
\hline & LED & 0.6896 & & & \\
\hline & TMW & 0.7229 & & & \\
\hline & TMG & 0.7399 & & & \\
\hline & TCS & 0.7679 & & & \\
\hline & CFR & 0.6442 & & & \\
\hline
\end{tabular}

\subsection{The Discriminant Validity Analysis}

Discriminant Validity refers to the level to which items can differentiate among different constructs to show that the items of different constructs are not overlapping. Additionally, discriminant validity of measures share variance between each individual construct and hence it should be higher than the variance shared among specific constructs. In this study, discriminant validity of measures was established through Fornell and Larcker's (1981) method, where the square root of AVE for all constructs was replaced at diagonal elements of relation matrix (Henseler, Ringl, \& Sarstedt, 2014). The detail is given below in Table 2.

Table 2. Discriminant validity analysis.

\begin{tabular}{ccccc}
\hline Items & JSB & JSA & SIB & SIA \\
\hline Job-Success Before COVID-19 (JSB) & $\mathbf{0 . 7 3}$ & & & \\
Job-Success After COVID-19 (JSA) & 0.23 & $\mathbf{0 . 7 9}$ & & \\
Soft-Skills Integration Before COVID-19 (SIB) & 0.36 & 0.36 & $\mathbf{0 . 8 2}$ & $\mathbf{0 . 7 6}$ \\
Soft-Skills Integration After COVID-19 (SIA) & 0.43 & 0.28 & 0.37 & \\
\hline
\end{tabular}

\subsection{The Path t-Values}

First of all, data is tested by evaluating the path t-values which are provided by the bootstrap routine. These values indicate the significance levels of each path and thereby the strength of support for the proposed hypothesis (Willis, 2018). Table below provides corresponding path t-values levels of significance. Result shows that there is significant variance among the soft-skills status for Low, Medium, High (L, M, H) and Increase, No Change, Increase (I, N, D) regarding job-market and integration at higher education curriculum before and after the COVID-19 crisis. The detail is given below in Table 3. 
Table 3. Soft-skills significance in higher education institutions.

\begin{tabular}{ccccc}
\hline & \multicolumn{4}{c}{ Soft-Skills Status Before \& } \\
\cline { 2 - 5 } Items & LMH & IND & LMH & IND \\
\cline { 2 - 5 } & $\mathrm{t}$-Values & $p$-Values & $\mathrm{t}$-Values & $p$-Values \\
\hline CRT & 2.812 & 0.197 & 5.835 & 0.372 \\
PAT & 2.543 & 0.052 & 5.742 & 0.403 \\
PER & 2.513 & 0.061 & 5.735 & 0.381 \\
ORG & 2.843 & 0.189 & 5.742 & 0.432 \\
ADP & 2.502 & 0.072 & 5.82 & 0.372 \\
LED & 2.817 & 0.075 & 5.761 & 0.462 \\
TMW & 2.513 & 0.173 & 5.745 & 0.381 \\
TMG & 2.533 & 0.053 & 5.842 & 0.432 \\
TCS & 2.802 & 0.169 & 5.638 & 0.391 \\
CFR & 2.791 & 0.171 & 2.791 & 0.197 \\
\hline
\end{tabular}

\section{Discussion \& Conclusion}

Study was based on observations of the people concerned with the academic environment of higher education institutions of Saudi Arabia. Study pointed out that the importance of soft-skills at higher education institutions has got more importance under COVID-19 pandemic crisis. Questionnaire was prepared to assess and evaluate the importance of soft-skills before and after the COVID-19 pandemic occurred by using Google Docs for data collection. Questionnaire had total six sections, first part was asking for basic demographic information of the participant i.e. Gender and Position in the academic environment. Second part had four sections each having 10 questions regarding the impact soft-skills before and after the COVID-19 pandemic crisis. Questions were distributed to Managers, Deans, HODs, Teachers, Students, Staff and Others. Questionnaire was focusing on the Job-Success before COVID-19 (JSB), Job-Success after COVID-19 (JSA), Soft-Skills Integration before COVID-19 (SIB) and Soft-Skills Integration after COVID-19 (SIA). Each section of questionnaire further has one question for each soft-skill to get the respondent's opinion with the Low, Medium and High, Increase, No Change and Decrease scales for evaluation purposes. Study results support the importance of soft-skills at higher education institutions in Kingdom of Saudi Arabia. Study results pointed out that Higher Education Ministry and Institutions have to observe it closely to initiate the role of the universities and colleges to improve the university graduate's prospects in terms of learning the soft skills to get better job opportunities in competitive Saudi job market. In this regards, descriptive analytical methods were applied for statistical measures like convergent validity, discriminant validity and path $\mathrm{t}$-values were performed on the data collected through the questionnaire. Study results proved that it will help the fresh graduates to learn the soft-skills and be ready to join 
the human resource at the work place. Study results showed that respondents were in opinion that soft-skills integration in higher education curriculum is very important and hence it should be added in all academic majors. Study results have shown significant evidence of respondents that Higher Education Institutions of Saudi Arabia must reconsider the integration of soft-skills in all study majors to enhance an improve the course objectives and learning outcomes as per the requirements of the job market during the COVID-19 crisis. In addition to this, role of soft-skills is very imperative in modern academic environment as it helps the university graduates to learn and apply the knowledge to real life situations in their work environment.

\section{Conflicts of Interest}

The authors declare no conflicts of interest regarding the publication of this paper.

\section{References}

Al Abduwani, R. (2012). The Value and Development of Soft Skills: The Case of Oman. International Journal of Information Technology and Business Management, 292, 77-86. http://www.jitbm.com

Al Khater, N. R. (2017). Department of Electronics and Computer Science a Model of a Private Sector Organisation's Intention to Adopt Cloud Computing in the Kingdom of Saudi Arabia By.

Bak, O., Jordan, C., \& Midgley, J. (2019). The Adoption of Soft Skills in Supply Chain and Understanding Their Current Role in Supply Chain Management Skills Agenda: A UK Perspective. Benchmarking, 26, 1063-1079. https://doi.org/10.1108/BIJ-05-2018-0118

Blackboard (2020). https://www.blackboard.com

Chondekar, N. R. (2019). Significance and Application of Soft Skill Development in Teacher Education. International Journal of Science and Research, 8, 1964-1966.

Cisco Webex (2020). https://www.webex.com

Hair, J. F. et al. (2014). Partial Least Squares Structural Equation Modeling (PLS-SEM): An Emerging Tool in Business Research. European Business Review, 26, 106-121. https://doi.org/10.1108/EBR-10-2013-0128

Hair, J. F., Babin, B. J., \& Krey, N. (2017). Covariance-Based Structural Equation Modeling in the Journal of Advertising: Review and Recommendations. Journal of Advertising, 46, 163-177. https://doi.org/10.1080/00913367.2017.1281777

Henseler, J., Ringle, C. M., \& Sarstedt, M. (2014). A New Criterion for Assessing Discriminant Validity in Variance-Based Structural Equation Modeling. Journal of the Academy of Marketing Science, 43, 115-135. https://doi.org/10.1007/s11747-014-0403-8

Marinakou, E., \& Giousmpasoglou, C. (2015). Stakeholders' Views on the Development of a Higher Education Hospitality Program in Bahrain: Challenges and Opportunities. Journal of Hospitality and Tourism Education, 27, 85-92. https://doi.org/10.1080/10963758.2015.1033104

Melluso, N. et al. (2020). Lights and Shadows of Covid-19, Technology and Industry 4.0 (pp. 1-12). https://pages.semanticscholar.org/coronavirus-research

Moodle (2020). https://moodle.com/ 
Pomeroy, W. (2014). Academic Analytics in Higher Education: Barriers to Adoption (pp. 1-190).

Saunders, M., Lewis, P., \& Thornhill, A. (2008). Research Methods for Business Students, Research Methods for Business Students.

Sharma, S. S. (2019). Role of Soft Skills in Tourism Industry in Saudi Arabia. International Journal of Engineering and Management Research, 9, 87-92. https://doi.org/10.31033/ijemr.9.4.14

Tang, K. N. (2020). The Importance of Soft Skills Acquisition by Teachers in Higher Education Institutions. Kasetsart Journal of Social Sciences, 41, 22-27.

Willis, R. (2018). An Analysis of the Moderating Effect of Age on Smartphone Adoption and Use in the United. In Association for Information Systems AIS Electronic Library (AISeL), UK Academy for Information Systems Conference Proceedings (pp. 1-27).

WizIQ (2020). https://www.wiziq.com

Yaacoub, H. K., Husseini, F., \& Choueiki, Z. (2011). Engineering Soft Skills: A Comparative Study between the GCC Area Demands and the ABET Requirements. Competition Forum, 9, 88-99.

https://search-proquest-com.ezproxy.lib.purdue.edu/docview/912502803/fulltextPDF/1 2AAF1EDD3E24EAAPQ/1?accountid=13360\%0Ahttps://search.proquest.com/docview /912502803? accountid $=28391$

Zoom (2020). https://zoom.us 